See Article page 15 .

\section{Commentary: A unique presentation of embolic phenomena from an ascending aortic pseudoaneurysm}

\author{
Melissa Taylor, MD, and Abe DeAnda, Jr, MD, \\ Galveston, Tex
}

Ascending aortic pseudoaneurysms (AAPs) are rare, with an incidence reported of only $0.5 \%$. A recent review of literature by Quevedo and colleagues ${ }^{1}$ identified 355 cases of AAP, $76 \%$ that were associated with a history of cardiac or aortic surgery, $5 \%$ were attributed to blunt chest trauma, $4.4 \%$ were attributed to inflammatory or autoimmune conditions, and $10.6 \%$ had no identifiable cause. The same study found that almost $73.8 \%$ were treated with open repair, $21.2 \%$ underwent endovascular repair, and the remainder were treated conservatively. ${ }^{1}$

AAPs are associated with myriad symptoms, including dyspnea and chest pain, and can progress to rupture or be a persistent source of infection or embolism. Often, they are asymptomatic and found incidentally on surveillance imaging after cardiac or aortic surgery.

De Martino and colleagues ${ }^{2}$ demonstrate an interesting presentation of AAPs as recurrent brain and retinal embolisms. It also highlights the need for evaluation with

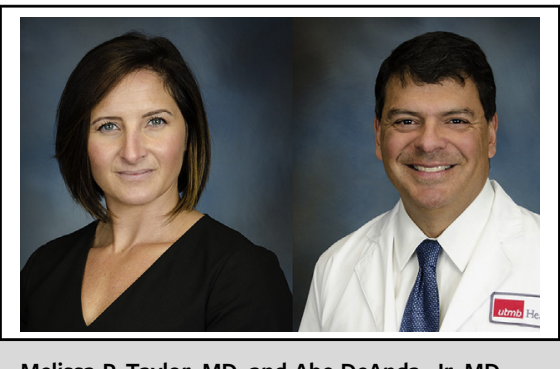

Melissa P. Taylor, MD, and Abe DeAnda, Jr, MD

\section{CENTRAL MESSAGE}

AAPs are rare but can cause devastating consequences. Patients with embolic phenomena should routinely have cardiac and aortic imaging to evaluate for anatomic causes such as AAPs.

imaging of cardiac and aortic anatomic abnormalities as possible source of embolic disease.

\section{References}

1. Quevedo HC, Santiago-Trinidad R, Castellanos J, Atianzar K, Anwar A, Abi Rafeh N. Systematic review of interventions to repair ascending aortic pseudoaneurysms. Oschsner J. 2014;14:576-85.

2. De Martino A, Falcetta G, Scioti G, Bortolotti U. A hidden aortic rupture heralded by recurrent brain and retinal embolism. J Thorac Cardiovasc Surg Tech. 2020;1: $15-6$.

From the Division of Cardiothoracic Surgery, University of Texas Medical Branch, Galveston, Tex.

Disclosures: Authors have nothing to disclose with regard to commercial support. Received for publication Sept 20, 2019; accepted for publication Oct 5, 2019; available ahead of print Nov 11, 2019.

Address for reprints: Abe DeAnda, Jr, MD, Division of Cardiothoracic Surgery, University of Texas Medical Branch-Galveston, 301 University Blvd, Galveston, TX 77551 (E-mail: abdeanda@utmb.edu).

JTCVS Techniques 2020;1:17

2666-2507

Copyright (c) 2019 The Author(s). Published by Elsevier Inc. on behalf of The American Association for Thoracic Surgery. This is an open access article under the CC BY-NC-ND license (http://creativecommons.org/licenses/by-nc-nd/4.0/).

https://doi.org/10.1016/j.xjtc.2019.11.001 